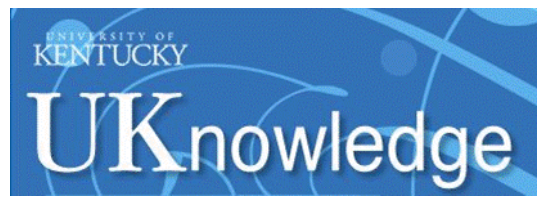

University of Kentucky

UKnowledge

Power and Energy Institute of Kentucky Faculty Publications

6-2017

\title{
Multilayer Concentrated Windings for Axial Flux PM Machines
}

Vandana Rallabandi

University of Kentucky, vandana.rallabandi@uky.edu

Narges Taran

University of Kentucky, narges.taran@uky.edu

Dan M. Ionel

University of Kentucky, dan.ionel@uky.edu

Follow this and additional works at: https://uknowledge.uky.edu/peik_facpub

Part of the Power and Energy Commons

Right click to open a feedback form in a new tab to let us know how this document benefits you.

\section{Repository Citation}

Rallabandi, Vandana; Taran, Narges; and Ionel, Dan M., "Multilayer Concentrated Windings for Axial Flux PM Machines" (2017). Power and Energy Institute of Kentucky Faculty Publications. 43.

https://uknowledge.uky.edu/peik_facpub/43

This Article is brought to you for free and open access by the Power and Energy Institute of Kentucky at UKnowledge. It has been accepted for inclusion in Power and Energy Institute of Kentucky Faculty Publications by an authorized administrator of UKnowledge. For more information, please contact UKnowledge@lsv.uky.edu. 


\title{
Multilayer Concentrated Windings for Axial Flux PM Machines
}

\author{
Digital Object Identifier (DOI)
}

https://doi.org/10.1109/TMAG.2017.2661312

\section{Notes/Citation Information}

Published in IEEE Transactions on Magnetics, v. 53, Issue: 6.

(c) 2017 IEEE Copyright Notice. "Personal use of this material is permitted. Permission from IEEE must be obtained for all other uses, in any current or future media, including reprinting/republishing this material for advertising or promotional purposes, creating new collective works, for resale or redistribution to servers or lists, or reuse of any copyrighted component of this work in other works."

The document available for download is the authors' manuscript version that is accepted for publication. The final published version is copyrighted by IEEE and available as: V. Rallabandi, N. Taran, and D. M. Ionel, "Multilayer Concentrated Windings for Axial Flux PM Machines," in IEEE Transactions on Magnetics, vol. 53, no. 6, pp. 1-4, June 2017, Art no. 8103104. doi: 10.1109/TMAG.2017.2661312 


\title{
Multilayer Concentrated Windings for Axial Flux PM Machines
}

\author{
Vandana Rallabandi, Narges Taran, and Dan M. Ionel, Fellow, IEEE \\ University of Kentucky, Department of Electrical and Computer Engineering, Lexington, KY, 40506, USA
}

\begin{abstract}
Coreless axial flux machines are of interest because of the absence of stator core losses and cogging torque. These machines generally employ concentrated windings. One of the challenges with such a winding is that the torque producing MMF component that corresponds to the fundamental of the magnet excitation is accompanied by substantial asynchronous components. These harmonics cause losses in the rotor core and magnets, which can become significant at high speeds. This paper proposes a new multilayer winding arrangement to eliminate the non torque producing MMF components. This winding is applied to a 12 coil 16 pole coreless axial flux machine. The efficacy of the winding is established by 3D finite element analysis.
\end{abstract}

Index Terms-Axial flux machines, MMF harmonics, multilayer windings.

\section{INTRODUCTION}

Axial flux permanent magnet (AFPM) machines with a coreless stator have advantages such as no stator core losses and very low torque ripple. The topology considered in this paper has concentrated stator coils and multiple rotor discs with surface mounted PMs (Fig. 1). The AFPM machines may be suitable for systems where weight is at a great premium, such as solar cars or high altitude solar airplanes [1], and have also been proposed for applications such as wind generators, pumps, and high speed generators [2], [3], [4].

The literature on the design of coreless AFPM machines includes, for example, the optimization using analytical and evolutionary methods [5] and the study of the rotor core thickness influence on the efficiency [6]. Other papers discuss the shaping of PMs to reduce the harmonics and the use of optimization techniques to reduce the torque ripple [7], [8]. In case of high speed coreless AFPM machines, a major limitation is the high eddy current loss in the stator coils, as these coils see the fundamental flux, rather than the slot leakage flux as in conventional machines. The use of thin parallel connected conductors, followed by twisting and transposing the wires reduces the $\mathrm{AC}$ loss in the windings [9]. Coreless machines can be designed with a large quantity of PM for applications where cost is not a main objective. In this case, the p.u. back EMF can be high and the p.u. synchronous inductance very low due to the large equivalent air-gap, such that the power factor is high. As an example, the calculated power factor for the machine considered in this paper is 0.98 .

In most of the literature, though some design issues have been addressed, it has been generally assumed that the loss in the rotor core and PMs is negligible, e.g. [6]. It has been

Manuscript received November 20, 2016.

The authors are with the SPARK Laboratory in Department of Electrical and Computer Engineering, University of Kentucky, Lexington, KY 40506 , USA. Vandana Rallabandi (email: vandana.rallabandi@uky.edu), Narges Taran (email: narges.taran@uky.edu), and Dan M. Ionel (email: dan.ionel@uky.edu).

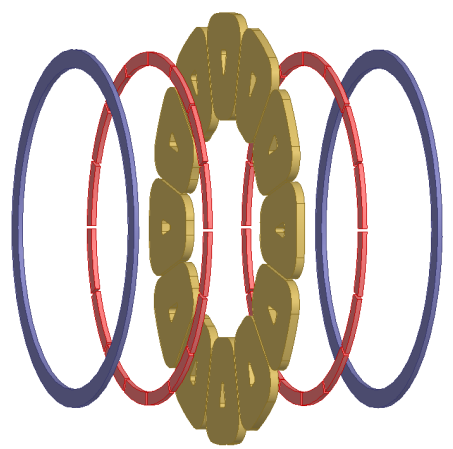

(a)

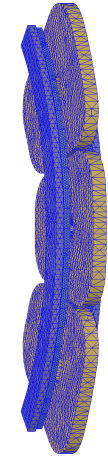

(b)
Fig. 1: (a) Exploded view of the coreless AFPM. The coils are mounted on a light weight supporting structure (not shown). The PMs (or a single multi-pole PM disc) are mounted on surface of a laminated silicon steel core, (b) Mesh suitable for 3D FEA calculation of rotor eddy current losses.

overlooked that coreless AFPM machines use concentrated windings, which have a significant proportion of asynchronous MMF harmonics. In some cases, the MMF component which interacts with the rotor to produce the torque is not the fundamental component. This is true for the example 12 coil 16 pole AFPM machine, wherein the MMF harmonic has a fundamental backward rotating 8 pole component, although the 16 pole component (i.e. the $2^{\text {nd }}$ harmonic) interacts with the rotor to produce torque [1]. This also applies to a 6 coil 10 pole machine in which the MMF has a fundamental 2 pole component, and the $5^{\text {th }}$ harmonic component interacts with the rotor to give a net torque, and also to a 6 coil machine with 14 poles, wherein the $7^{\text {th }}$ harmonic MMF leads to torque production. Thus, all these machines contain low order asynchronous MMF components would induce currents in the rotor back and PMs, causing losses which would become prohibitively high in high speed applications.

This paper proposes the use of novel multilayer winding arrangements to mitigate the MMF harmonics in a coreless AFPM machine. Although multilayer windings have been proposed for fractional slot concentrated winding PMSM [10], [11], they have not been hitherto applied to coreless AFPM machines. In conventional slotted machines, the winding layers can only be shifted by multiples of the stator slot pitch, while in coreless AFPMS, any shifting angle is possible.

This paper illustrates that in case of a 12 coil 16 pole coreless AFPM machine, a 2 layer winding with the layers shifted by $45^{\circ}$ mechanical eliminates the asynchronous 8 pole component. Also, a 4 layer winding with the layers shifted by $22.5^{\circ}$ mechanical eliminates the 8 pole component, along with higher order asynchronous components. The elimination of harmonics from the MMF is proved by a winding function 


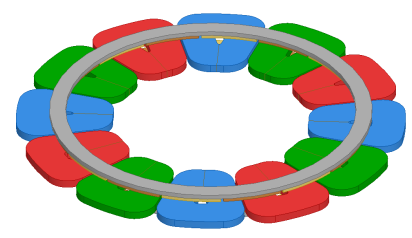

(a)

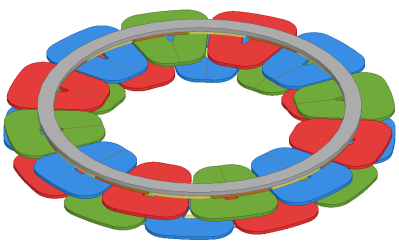

(b)

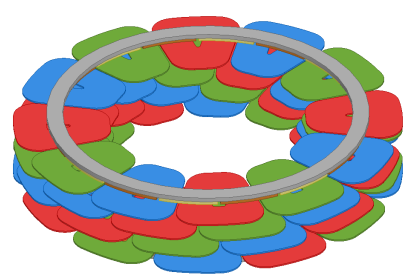

(c)

Fig. 2: Air-gap concentrated winding. (a) Single layer winding. (b) Double layer winding, shifted by 45 mechanical degrees circumferentially. (c) Four layer winding, incrementally shifted by 22.5 mechanical degrees with polarity of adjacent layers reversed.

based approach. The resulting elimination of asynchronous components from the air-gap flux density, and subsequent reduction of rotor losses is verified by 3D finite element analysis (FEA). ANSYS Electronics Desktop is used for the 3D FEA. Analytical equations to identify the number of layers and the shifting angle for coreless AFPM machines with other stator coil and rotor pole combinations are derived.

\section{ELIMINATION OF MMF HARMONICS BY MULTI-LAYER WINDINGS}

A representation of multi-layer concentrated windings applied to the coreless AFPM machine is shown (Fig. 2). Winding function analysis is used to explain the reduction of harmonics achieved by multi-layer windings. The analysis is exemplified for a 12 coil 16 pole coreless AFPM machine. From the graphical representation of the winding function for this machine (Fig. 3), the fundamental component corresponds to 8 poles. It can be expressed as a Fourier Series as

$$
n=\frac{3}{\nu \pi} \sum_{\nu=1}^{\infty} \sin \left(4 \nu \theta+\frac{\pi}{3}\right),
$$

where $\nu$ takes values of all integers except the multiples of 3 . The magnitude of the 8 pole component is $\frac{3}{\pi}$. Suppose that a winding layer shifted circumferentially by $\Delta \theta$ is placed axially adjacent to the first layer. The fundamental component of the winding function for this layer can be expressed using (1) as

$$
n_{1}=\frac{3}{\pi} \sin \left[4(\theta-\Delta \theta)+\frac{\pi}{3}\right]
$$

The resultant winding function is the sum of two layers winding functions. To eliminate the fundamental component,

$$
4 \theta=4(\theta-\Delta \theta)+\pi
$$

Giving,

$$
\Delta \theta=\frac{\pi}{4}
$$

Thus, shifting adjacent layers by $45^{\circ}$ mechanical would eliminate the fundamental component of the MMF. The effect on the synchronous 16 pole component is evaluated as follows

$$
n_{2}=\frac{3}{2 \pi} \sin \left(8 \theta+\frac{\pi}{3}\right)+\frac{3}{2 \pi} \sin \left(8 \theta-8 \frac{\pi}{4}+\frac{\pi}{3}\right),
$$

which gives,

$$
n_{2}=\frac{3}{\pi} \sin \left(8 \theta-\frac{\pi}{3}\right)
$$

Thus, the magnitude of the synchronous MMF component is added in phase in the two layers shifted by $45^{\circ}$. Considering that each winding layer has half the total turns, it can be concluded that the useful torque producing MMF component remains unchanged. It can also be shown that the higher order components are unaffected. Proceeding similarly, for a 4 layer winding shifted $22.5^{\circ}$ mechanical, with the polarity of adjacent layers reversed, the winding function is given by,

$$
\begin{array}{r}
n_{\nu}=\frac{3}{\nu \pi} \sin \left(4 \nu \theta+\frac{\pi}{3}\right)-\frac{3}{\nu \pi} \sin \left[4 \nu\left(\theta-\frac{\pi}{8}\right)+\frac{\pi}{3}\right] \\
+\frac{3}{\nu \pi} \sin \left[4 \nu\left(\theta-2 \frac{\pi}{8}\right)+\frac{\pi}{3}\right]-\frac{3}{\nu \pi} \sin \left[4 \nu\left(\theta-3 \frac{\pi}{8}\right)+\frac{\pi}{3}\right]
\end{array}
$$

It can be shown that this term evaluates to 0 for all $\nu$, except $\nu=2$, i.e. the synchronous torque producing component, indicating that this type of winding arrangement successfully eliminates asynchronous MMF components.

The circumferentially shifted concentrated winding has the effect of creating additional angular positions for the placement of the coil sides. Use of concentrated winding does not allow the placement of coils sides of a phase every $360^{\circ}$ electrical apart, leading to an MMF with a fundamental component of a different number of poles than the rotor. In the two layer winding, the second layer allows the repetition of a phase every $360^{\circ}$ electrical, thereby eliminating sub-harmonics. Thus, in general, the phase shift between adjacent layers required for the repetition of a phase every $360^{\circ}$ electrical (which would result in elimination of the fundamental asynchronous component) is given by

$$
\Delta \theta=\frac{4 \pi}{P}
$$

For this case, the number of layers is given by

$$
L=\frac{m P}{2 \times N_{c}},
$$

where $N_{c}$ is the number of coils, m; the number of phases and $\mathrm{P}$; the number of poles.

Repetition of a phase every $180^{\circ}$ and $360^{\circ}$ electrical degrees further reduces harmonics. This is accomplished by shifting circumferentially and doubling the numbers of layers with

$$
\Delta \theta=\frac{2 \pi}{P}, \quad L=\frac{m P}{N_{c}}
$$

If adjacent layers are shifted by $180^{\circ}$ electrical, the coil connections in adjacent layers need to be reversed. On the other hand, if the adjacent layers are shifted by $360^{\circ}$ electrical, then coil connections in adjacent layers should be maintained 


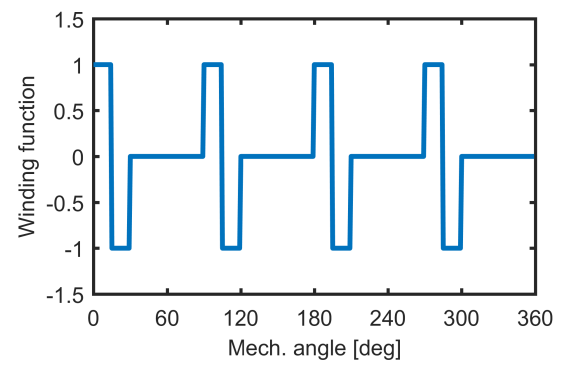

Fig. 3: Winding function for the 'a' phase of 12 coil 16 pole coreless AFPM machine.

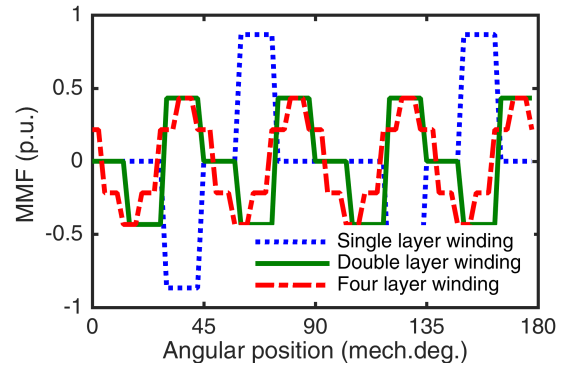

Fig. 4: MMF for the different winding arrangements as obtained from analytical calculation. Elimination of the 8 pole component is observed for the multilayer windings.

TABLE I: Winding factors $\left(k_{w}\right)$ of different harmonics $(\nu)$ for the proposed winding arrangements.

\begin{tabular}{lrrr}
\hline Harmonic Order & Single layer & Two layer & Four layer \\
\hline 1 & -0.48 & 0.00 & 0.00 \\
2 & 0.72 & 0.72 & 0.72 \\
4 & -0.36 & -0.36 & 0.00 \\
7 & -0.48 & 0.00 & 0.00 \\
8 & 0.72 & 0.72 & 0.00 \\
10 & -0.36 & -0.36 & -0.36 \\
14 & 0.72 & 0.72 & 0.72 \\
\hline
\end{tabular}

the same. The MMF is given by the product of the winding functions with the 3 phase currents (Fig. 4).

The winding factor is given as the product of coil spread factor and pitch factor [1]. The coil spread factor is obtained as the ratio of the EMFs induced over a coil side to the maximum possible EMF that could have been induced, i.e.

$$
k_{s}=\frac{\int_{0}^{\theta_{s}} e^{j \theta} d \theta}{\int_{0}^{\theta_{s}} d \theta}=\frac{2 \sin \left(\theta_{s} / 2\right)}{\theta_{s}}
$$

The pitch factor is obtained as the ratio of vector sum of the EMFs in two coil sides comprising a coil, to the algebraic sum, i.e.

$$
k_{p}=\frac{E \angle 0-E \angle \theta_{p}}{2 E}=\sin \left(\theta_{p} / 2\right),
$$

where, $\theta_{s}$ is the (electrical) angular spread of the coil side, $\theta_{p}$; the (electrical) coil pitch and $E$; the EMF induced in a single coil side. The winding function $k_{w}$ is given as,

$$
k_{w}=k_{p} \times k_{s}
$$

The harmonic winding factors for single and multi-layer arrangements for the example 12 coil 16 pole coreless AFPM machine and summarized in Table I.

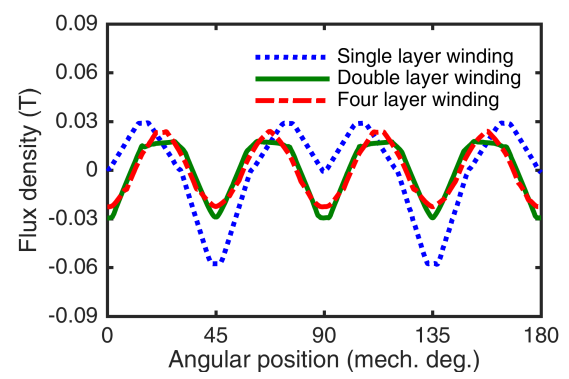

Fig. 5: The air-gap flux density due to armature reaction for the different winding arrangements as obtained from 3D finite element analysis. Elimination of the 8 pole component is observed for the multilayer windings.

TABLE II: Rotor loss at 10,000rpm obtained from 3D FEA.

\begin{tabular}{lrr}
\hline Single layer & Two layer & Four layer \\
\hline $91 \mathrm{~W}$ & $3.1 \mathrm{~W}$ & $0.2 \mathrm{~W}$ \\
\hline
\end{tabular}

\section{Three-Dimensional Finite Element Analysis}

Typically, the winding function analysis can be used to predict the air-gap flux density for machines with smaller airgaps [12]. In the case of coreless AFPM machines, the air-gap is significantly large, and flux paths are three-dimensional. Therefore, 3D FEA is used to evaluate the flux density distribution to verify the elimination of asynchronous components. The FEA model has over 1 million mesh elements. The dimensions of the FE mesh for eddy current calculations have to correlate with the depth of penetration and hence with the physical dimensions, materials and machine rotating frequency. The active outer diameter and active axial length of the model are $340 \mathrm{~mm}$ and $147 \mathrm{~mm}$, respectively. The PM dimensions are $53.6 \times 10.5 \times 4.0 \mathrm{~mm}$.

The utilization of multiple winding layers, each with a A+ A- B + B- C+ C- pattern, greatly reduces and eliminates the asynchronous components from the armature reaction air-gap flux density (Fig. 5), reduces the rotor core flux density 6) and the eddy currents in the PM (Fig. 7), and significantly lowers rotor losses (Table II).

The simplified winding function analysis predicts the amplitude of the back EMF is substantially the same for the multilayer windings are the same as the single layer. The 3D FE calculations, which take into account the effect of a substantially large air-gap, yield $47.7 \mathrm{~V}, 45.7 \mathrm{~V}$ and $45.6 \mathrm{~V}$ for the amplitude back emf of the single, double and four layer winding, respectively (Fig. 8). As an overall result, the multi-layer machines are expected to have comparable output torque and higher efficiency than single layer designs.

\section{CONCLUSION}

The use of multilayer windings is extended in a novel manner to coreless AFPM machines with concentrated windings and the design proposal is supported by analysis using winding functions and 3D FEA. Unlike in conventional machines wherein the winding layers can only be shifted by the stator slot pitch or multiples, in a coreless AFPM a shifting angle resulting in elimination of the highest asyncrhonous MMF components can be employed. It is found that an appropriate selection of the number of layers and shifting angle 


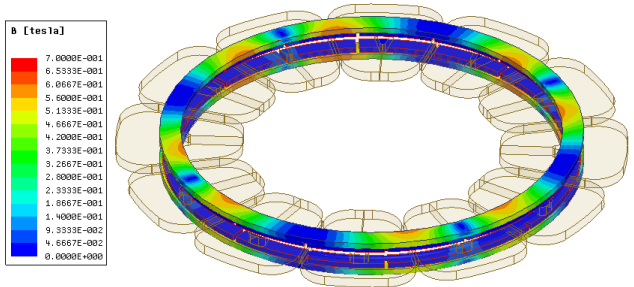

(a)

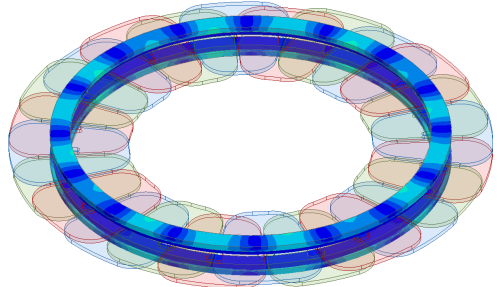

(b)

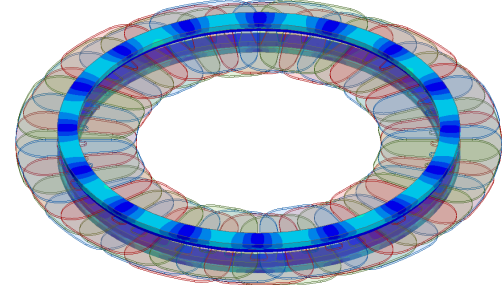

(c)

Fig. 6: The flux density in the rotor core due to the armature reaction excitation alone with (a) single layer, (b) two layer, and (c) four layer stator windings, all represented on the same scale. As predicted by the analysis, the flux density for multi-layer winding designs is lower leading to reduced power losses.

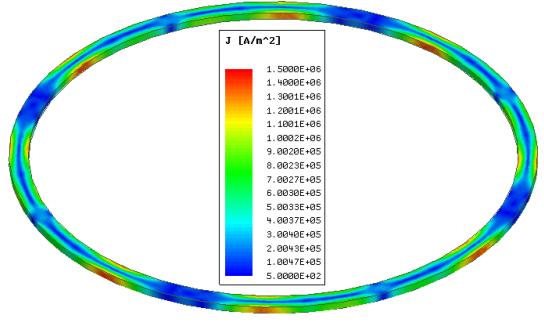

(a)

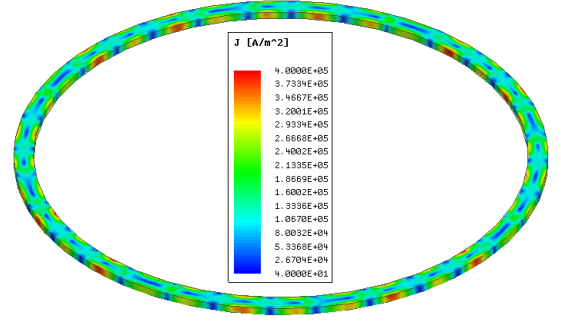

(b)

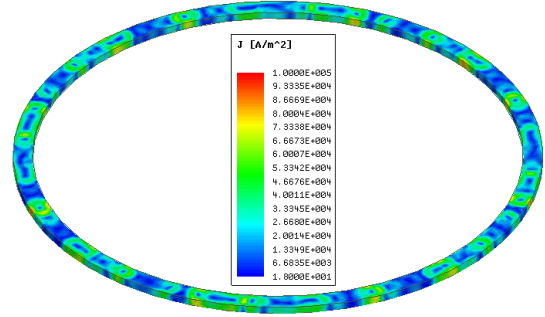

(c)

Fig. 7: Eddy current density in the PM rotor disc with (a) single layer winding with maximum of $1.5 \mathrm{~A} / \mathrm{mm}^{2}$, (b) two layer winding with maximum of 0.4 $\mathrm{A} / \mathrm{mm}^{2}$, and (c) four layer winding with maximum of $0.1 \mathrm{~A} / \mathrm{mm}^{2}$. The values are much lower for the multi-layer winding designs, for which the eddy current circulating paths are also shorter leading to reduced power losses.

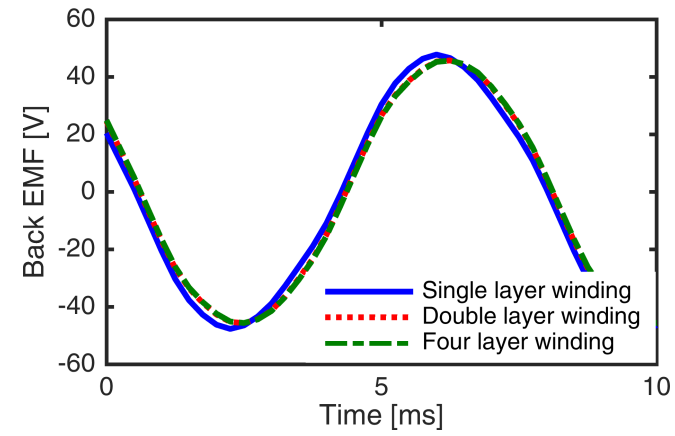

Fig. 8: Per phase open circuit voltage for single and multilayer windings. The magnitude of the fundamental component remains virtually unchanged verifying that winding factor for the 16 pole component is substantially unaffected by the shifting, as predicted by the analytical calculations.

can be used to obtain a nearly sinusoidal MMF distribution, as produced by distributed windings. Analytical equations which identify the number of winding layers, and the shifting angle for different stator coil, rotor pole combinations are derived. It is shown through 3D FEA that in a 12 coil 16 pole coreless AFPM machine, the rotor losses reduce to less than $5 \%$ of their original value with the use of the proposed multilayer concentrated windings.

\section{ACKNOWLEDGMENTS}

The support of University of Kentucky, the L. Stanley Pigman endowment, of ANSYS, Inc. and the expert advice of Dr. Ping Zhou are gratefully acknowledged.

\section{REFERENCES}

[1] R. Hill-Cottingham, P. Coles, J. Eastham, F. Profumo, A. Tenconi, and G. Gianolio, "Multi-disc axial flux stratospheric aircraft propeller drive," in Industry Applications Conference, vol. 3, Sept 2001, pp. 1634-1639.
[2] T. F. Chan and L. L. Lai, "An axial-flux permanent-magnet synchronous generator for a direct-coupled wind-turbine system," IEEE Transactions on Energy Conversion, vol. 22, no. 1, pp. 86-94, March 2007.

[3] G. J. Yan, L. Y. Hsu, J. H. Wang, M. C. Tsai, and X. Y. Wu, "Axial-flux permanent magnet brushless motor for slim vortex pumps," IEEE Transactions on Magnetics, vol. 45, no. 10, pp. 4732-4735, Oct 2009.

[4] W. Fei, P. C. K. Luk, and K. Jinupun, "Design and analysis of high-speed coreless axial flux permanent magnet generator with circular magnets and coils," IET Electric Power Applications, vol. 4, no. 9, pp. 739-747, Nov 2010

[5] P. Virti, M. Vrai, and G. Papa, "Design of an axial flux permanent magnet synchronous machine using analytical method and evolutionary optimization," IEEE Transactions on Energy Conversion, vol. 31, no. 1, pp. 150-158, March 2016.

[6] M. Sadeghierad, A. Darabi, H. Lesani, and H. Monsef, "Rotor yoke thickness of coreless high-speed axial-flux permanent magnet generator," IEEE Transactions on Magnetics, vol. 45, no. 4, pp. 2032-2037, April 2009.

[7] C. C. Hwang, P. L. Li, F. C. Chuang, C. T. Liu, and K. H. Huang, "Optimization for reduction of torque ripple in an axial flux permanent magnet machine," IEEE Transactions on Magnetics, vol. 45, no. 3, pp. 1760-1763, March 2009.

[8] T. El-Hassan and P. C. Luk, "Magnet topology optimization to reduce harmonics in high speed axial flux generators," in Magnetics Conference, 2003. INTERMAG 2003. IEEE International, March 2003, pp. GS-03.

[9] R.-J. Wang and M. J. Kamper, "Calculation of eddy current loss in axial field permanent-magnet machine with coreless stator," IEEE Transactions on Energy Conversion, vol. 19, no. 3, pp. 532-538, Sept 2004.

[10] A. S. Abdel-Khalik, S. Ahmed, and A. M. Massoud, "Effect of multilayer windings with different stator winding connections on interior pm machines for ev applications," IEEE Transactions on Magnetics, vol. 52, no. 2, pp. 1-7, Feb 2016.

[11] A. Sun, J. Li, R. Qu, and D. Li, "Effect of multilayer windings on rotor losses of interior permanent magnet generator with fractional-slot concentrated-windings," IEEE Transactions on Magnetics, vol. 50, no. 11, pp. 1-4, Nov 2014.

[12] G. Heins, D. M. Ionel, and M. Thiele, "Winding factors and magnetic fields in permanent-magnet brushless machines with concentrated windings and modular stator cores," IEEE Transactions on Industry Applications, vol. 51, no. 4, pp. 2924-2932, July 2015. 
Vandana Rallabandi (M'17) is a Post-doctoral Researcher in the SPARK Laboratory, Electrical and Computer Engineering Department, University of Kentucky, Lexington, KY. Prior to this, she was a Research Engineer at the General Electric (GE) Global Research Center in Bangalore, India. She obtained the Masters and Ph.D. degrees at the Indian Institute of Technology Bombay, India. She has published over forty journal and conference proceedings papers, including three that received awards from IEEE, IET, and ICRERA, respectively, co-authored four book chapters, and has more than five invention disclosures and patent pending applications. She has been a reviewer for IEEE transactions on Industry Applications, Energy Conversion, Power Electronics, Industrial Electronics and Magnetics, IET Electric Power Applications and Electric Power Components and Systems. Her areas of work include electric machines, power electronics drives, renewable energy devices and systems, energy storage, and power systems.

Narges Taran (S'16) received her M.S. degree in Power Electronics and Electric Machines from K. N. Toosi University of Technology, Tehran, Iran, in 2014. In 2016, she started her $\mathrm{PhD}$ studies at University of Kentucky, Lexington, KY, were she is currently a PhD candidate. Her research focuses on electric machines, computational electromagnetics, optimization methodologies, and power electronic drives.

Dan M. Ionel (M'91-SM'01-F'13) received the M.Eng. and Ph.D. degrees in electrical engineering from the Polytechnic University of Bucharest, Bucharest, Romania. His doctoral program included a Leverhulme Visiting Fellowship at the University of Bath, Bath, U.K. He was a Post-Doctoral Researcher with the SPEED Laboratory, University of Glasgow, Glasgow, U.K.
He is currently Professor of Electrical Engineering and the L. Stanley Pigman Chair in Power with the University of Kentucky, Lexington, KY, where he also serves as the Director of the Power and Energy Institute of Kentucky (PEIK) and of the SPARK Laboratory. He previously worked in industry, most recently as a Chief Engineer with Regal Beloit, Corp., Grafton, WI, USA, and, before that, as the Chief Scientist for Vestas Wind Turbines. Concurrently, he also was a Visiting and Research Professor at the University of Wisconsin and Marquette University, Milwaukee, WI, USA. He contributed to technology developments with long lasting industrial impact, holds more than thirty patents, and published more than two hundred technical papers, including four that received IEEE awards.

Dr. Ionel was the inaugural Chair of the IEEE Industry Applications Society Renewable and Sustainable Energy Conversion Systems Committee and an Editor of the IEEE TRANSACTIONS ON SUSTAINABLE ENERGY. $\mathrm{He}$ is the Editor in-Chief of the Electric Power Components and Systems Journal, the Past Chair of the IEEE Power and Energy Society Electric Motor Subcommittee, and was the General Chair of the IEEE 2017 Anniversary Edition of the International Conference on Electrical Machines and Drives. 